\title{
Zootechnical Fattening Protocol for Mixed Breed Young Bulls with Zoo-sanitary Management System
}

\author{
Hani SAOUDI ${ }^{*}$, Amel SAOUDI ${ }^{2}$, Adila FARTAS ${ }^{3}$, Leila AOUN ${ }^{1}$ \\ ${ }^{1}$ Faculty of Nature and Life Sciences, Department of Veterinary Sciences, University Chadli Ben Djdid El -Tarf, \\ Laboratory of Epidemiosurveillance, Health, Production, Reproduction, Cell Therapy and Experimentation with \\ Domestic and Wild Animals, BP. 36000 El Tarf. Algeria \\ ${ }^{2}$ Faculty of sciences, University of Badji Mokhtar Annaba, Laboratory of Marine and Coastal Ecosystems, BP. 23000 \\ Sidi Amar, Annaba. Algeria \\ ${ }^{3}$ Faculty of sciences, University of Badji Mokhtar Annaba, Laboratory of Applied Animal Biology, BP. 23000 Sidi Amar, \\ Annaba. Algeria \\ * Corresponding author: Hani SAOUD e-mail: hanisaoudi9@gmail.com
}

RESEARCH ARTICLE

\begin{abstract}
The objective of this study is to reduce the cost of raising beef cattle in Algeria by proposing a Zootechnical fattening protocol for breeders. The study was carried out on mixed-breed young bulls (Charolais x local breeds). Food rations were distributed daily; the first ration (F1) was made up of soybeans while the second ration (F2) was made of tomato pulp supplemented with sodium bicarbonate. Parameters calculated were the Average Daily Gain (ADG), quantity of faeces eliminated, and weight of each bull. The ADG results shown in F1 and F2 are close. The addition of Sodium Bicarbonate in the F2 ration helps to alleviate certain digestive disorders, particularly acidosis and diarrhoea; therefore, reducing the production costs per $\mathrm{kg}$ of meat obtained from bulls fed with tomato which was available annually. The proposed protocol improved fillet yield and lowered the cost per $\mathrm{kg}$ of meat. It can be applied internationally in any rudimentary livestock farm.
\end{abstract}

Keywords: breeders; average daily gain (ADG); tomato pulp; zootechnical standards; Algeria.

Received: 11 October 2020 Accepted: 16 February 2021 Published: 14 May 2021

DOI:

10.15835/buasvmcn-vm:2020.0041

\section{INTRODUCTION}

The increasing world population contributes to a strong demand for animal proteins (FAO et al., 2013). The fattening of beef cattle contributes to the economy of third world countries by optimizing zootechnical standards and producing good quality meat without risk to public health and the environment. This is not the case in Algeria where livestock farming remained at a traditional stage (Feliachi, 2003). In Algeria, more than 13.72 million quintals of tomatoes are produced each year (2017-2018) (Algerian Ministry of Agriculture, 2018). It is considered a source of low cost livestock feed that is available annually. Global production of red meat is 336.4 million tonnes (FAO, 2018). In Algeria, local production was two million cows according to Chikhi and Bencrif, (2016) which corresponds to 300,000 tonnes of beef according to our estimate. According to culinary tradition in Algeria, the head and offal are eaten. The Algerian state imported 28,000 tons during the first four months of 2019 in preparation of periods of high demand (Ramadan and religious holidays) to compensate for the deficit, because meat in Algeria is not imported throughout the year.

Algerian consumers consider meat among the most expensive foods sold at 1600 DZD per kilogram. Primary producers explain this high price by using rations made from imported soybeans. In this context, and in the absence of an effective policy aimed at promoting the beef cattle fattening sector, the use of a locally produced ration such as tomato pulp becomes a necessity in order to reduce the costs for breeders and reduce the selling price per kilogram of meat.. 
The objective of this study was to follow the Average Daily Gain (ADG) of mixed breed young bulls with regard to two mixed feed rations F1 (soybean, corn) and F2 (local tomato pulp with sodium bicarbonate, corn), and propose a zootechnical fattening protocol which aims to help breeders to better manage their production and produce healthy meat at a lower cost.

\section{MATERIALS AND METHODS}

The study was carried out in the Zrizer region, a commune of El-besbes, province of El-Tarf, north-eastern Algeria (Figure 1). This region was characterized by a humid climate and significant vegetation in the rainy season.

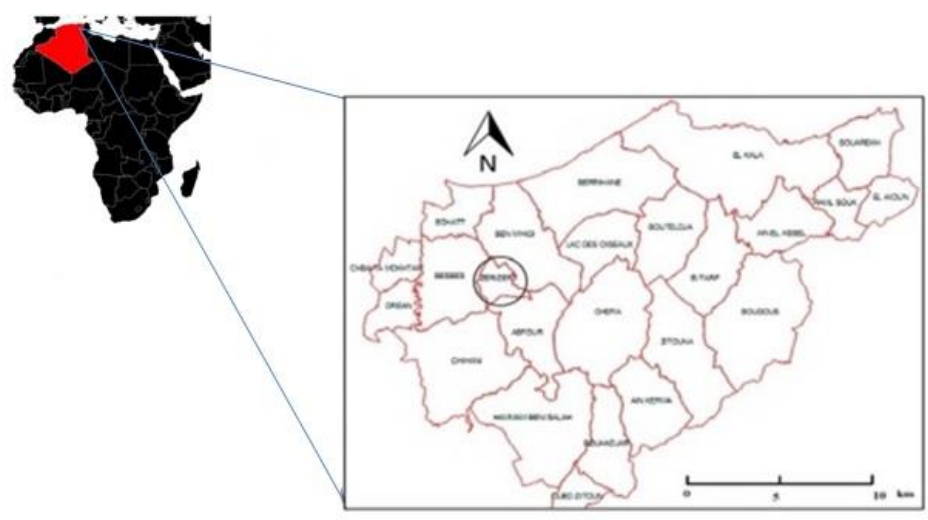

Figure 1. Study area in the Zrizer region, province of EL Tarf (Mapinfo, 2019)

Our experiment was carried out in a private farm containing one hundred male young bulls of mixed breed (Charolais $\mathrm{x}$ local breed). The breeding building had an area of $250 \mathrm{~m} 2$ organized in two cow alleys each alley contained fifty bulls separated by a system of metal partitions. The cattle feeders were constructed of concrete; the animals were raised in intensive fattening mode. Watering frequency was once a day in winter and twice a day in summer. The floor was concrete with a slope towards the center of the barn to facilitate urine drainage and collection as well as cleaning and brushing of young bulls.

In their first four days of life all the animals received only colostrum to ensure their passive immunity to be built properly. Their further diet consisted in a mixture of colostrum and cow milk for the next three months. In their fourth month of life the calves were gradually transitioned to solid feed providing them both milk and solid feed (hay). At the age of four months they received internal and external antiparasitic treatment (Valbendazol and 500mg Phoxim) finally the animals were given exclusively solid feed. The fatting protocol started at the age of six months and lasted for a period of months.

Fifty young bulls were fed rations of F1, and the fifty others were fed rations of F2 daily (Table 1).

Table 1. Food composition of the ration distributed to the young bulls

\begin{tabular}{|c|c|c|c|}
\hline Feed $1($ F1) & Physical form of the food & Composition & $\begin{array}{c}\text { Concentration } \\
\text { (\% weight) }\end{array}$ \\
\hline & Flour concentrate & $\begin{array}{c}\text { Corn } \\
\text { Soy } \\
\text { Barley } \\
\text { Salt } \\
\text { Trace elements } \\
\text { Vitamin Mineral Complex } \\
\text { Yeasts }\end{array}$ & $\begin{array}{c}65 \\
20 \\
13 \\
1 \\
0,1 \\
1 \\
0,2\end{array}$ \\
\hline $\begin{array}{c}\text { Feed } 2 \\
(\text { F2) }\end{array}$ & Fermentable dehydrated & $\begin{array}{c}\text { Corn } \\
\text { Tomato pulp } \\
\text { Barley } \\
\text { Salt+Sodium bicarbonate } \\
\text { Trace elements } \\
\text { Vitamin Mineral Complex }\end{array}$ & $\begin{array}{c}60 \\
28 \\
10 \\
1 \\
0,1 \\
1 \\
\end{array}$ \\
\hline
\end{tabular}

The diet started at $1.5 \mathrm{~kg}$ and gradually increased to $7 \mathrm{~kg}$ at the end process of the fattening. The goal of sodium bicarbonate supplementation was to balance the ruminal $\mathrm{pH}$ needed to promote microbial digestion to reduce the problem of diarrhoea and acidosis often encountered in cattle herds using rations made up of tomato pulp only (Sauvant et al., 2015). 
To assess the effectiveness of the current zootechnical breeding protocol, three parameters were calculated: The Average Daily Gain (ADG), quantity of faeces eliminated (kg) and the weight of each young bull (kg).

The calculation of the weight carried out by a cattle weight tape which makes it possible to directly estimate the weight of the cattle, by measuring the circumference of the chest taken just behind the front leg.

Concerning the calculation of faeces eliminated for each bull calves was carried out manually by several scales and with the help of farm staff who received money to help collect these measurements.

Average Daily Gain (ADG)

The average daily gain (ADG) expressed in $\mathrm{kg}$ of body weight / day.

\section{Statistical analysis}

The statistical study was carried out with MINITAB software version 16 using average values for the three parameters studied. Analysis of the variance (ANOVA) between the quantity of feed distributed once with each of the other parameters; the weight of the young bulls, the average ADG and quantity of faeces eliminated (Dagneli, 2013). The significance threshold was $\mathrm{p} \leq 0.05$.

\section{RESULTS AND DISCUSSIONS}

It was important to note that in the meat sector in Algeria the trend of early weaning was gaining momentum. This was the case of the 100 young bulls studied that showed a good net yield. This agrees with the opinion of Blanco et al. (2008) who confirms that the early weaning contributes to the modification of the fattening performance of young bulls without modifying the organoleptic quality of the meat.

The food transition period of our hundred bulls (mixed Algerian breed) was four weeks according to their zoo sanitary documents. Which allows a gradual transition from liquid diet (milk) to solid diet (mixed ration). This was in line with the work of Górka et al., (2017) which shows that a gastrointestinal transition period of three weeks was sufficient for a balanced weaning.

Results of the comparison between average weights, average ADG and average quantity of faeces eliminated, in relation to the amount of food distributed by type of food ration

The results obtained from the analysis of variance between the average ADG and the quantity of feed distributed show significant differences $(\mathrm{p} \leq 0.05)$, we can say that the ADG changes were in accordance with the type of mixed ration in favour of F1. In regards to the quantity of faeces eliminated, the young bulls fed with an F1 ration had a lower quantity of faeces eliminated $(1.8 \mathrm{~kg}$ ) compared to the bulls fed with the F2 ration which had on average $2 \mathrm{~kg}$ per day (Table 2).

Table 2. Application of ANOVA test on the average weight of young bulls, average ADG and quantity of faeces eliminated

\begin{tabular}{llllll}
\hline Variables & \multicolumn{2}{c}{ Feeds } & MS & F observed & p \\
\hline \multirow{2}{*}{\begin{tabular}{l} 
Average weight $(\mathbf{k g})$ \\
\cline { 2 - 6 } Average ADG
\end{tabular}} & 321 & $\mathrm{~F} 1$ & 456968 & 105 & 0 \\
\cline { 2 - 6 } & 317 & $\mathrm{~F} 2$ & 437954 & 135 & 0 \\
\hline $\begin{array}{l}\text { Average quantity of } \\
\text { faeces eliminated }(\mathbf{k g})\end{array}$ & 1094 & $\mathrm{~F} 1$ & 5305110 & 507 & 0 \\
\hline
\end{tabular}

MS: Medium square, p: probability, Significant $\mathrm{P} \leq 0.05$.

The gradual introduction of the mixed ration promotes the development of the third gastric pouch and the installation of microorganisms necessary for the proper functioning of the rumen (Wang et al., 2017) which contributes to the growth of young bulls expressed by the increase in mean ADG (Table 2).

The ANOVA results showed that there were significant differences between the quantity of faeces elimination delivered by the hundred young bulls and the ration distributed (F1 and F2) as mentioned by Senevirathne et al (2017).

The quantity of faeces eliminated (Table 2) was variable depending on the physical form of the food distributed (Table 1) this being in agreement with the results of Imani et al (2017) and in contradiction with the work of Pazoki et al., 2017.

The F1 ration balanced at 65\% / 20\% (Corn / Soybean; imported), showed a good net yield due to the metabolism which provides the energy necessary for the growth and muscle production of the young bulls. This energy is available in the form of Volatile Fatty Acid (VFA). The proteins contained in the food ration undergo a degradation into amino acids which are deaminated and provide the ammonia used by different groups of microorganisms to synthesize their own proteins (Genzebu and Tesfay, 2015). F2 remains a good alternative due to the acceptable net yields of ADG F2 (961 g / d) that it 
supplies in addition to the annual availability of tomato pulp in Algeria. It also has the advantage of being easy to mix into the ration at a low cost and remains an ecological substitute since it does not contain chemical preservatives such as the case of soybeans imported from Argentina (ONAB, 2019).

\section{Results of the change in the average ADG: for the two types of rations}

Figure 2 shows an increase from one month to another in the ADG-s of the two experimental groups of young bulls receiving rations $F 1$ and $F 2$. The ADG F2 showed a lower yield than ADG F1 especially during the three last months of the fattening cycle. Despite that ADG F2 values remain acceptable.

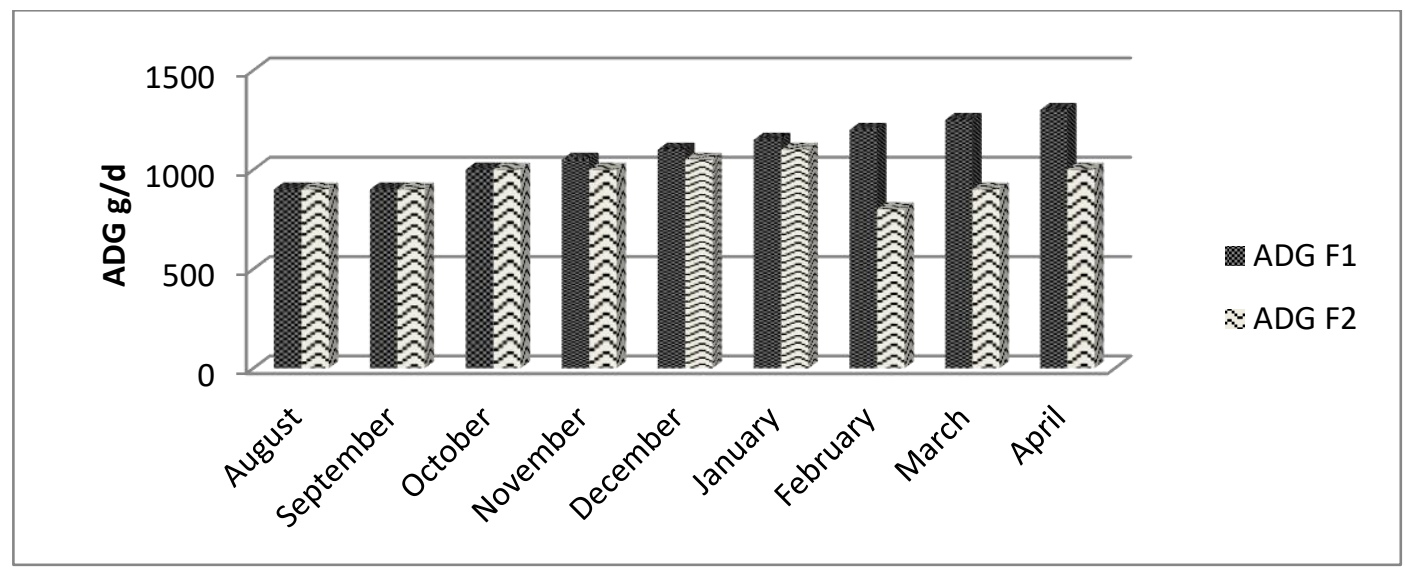

Figure 2. Variation of the monthly evolution of ADG-s of young bulls according by food ration distributed F1 and F2.

The ADG-s (Figure 2) were inferior to the average ADG in other breeds as reported by Sultan et al. (2009) in the Charolais breed (1300-1800 g / d), and (1800-2100g / d) in Belgian Blue breed.

ADGF1 and ADGF2 were close due to the addition of sodium bicarbonate in the F2 mixture ration which helps to fight muscular atrophy and digestive disorders as reported by Kazemi-Bonchenari et al., (2017).

In local breeding farms we noted the absence of an applied zootechnical protocol (Feliachi, 2003). In addition, the use of veterinary products associated with the application of good breeding and housing practices help the fight against the stress caused in young bulls by overcrowding during their fattening cycle.

In order to better guide breeders to optimize their zootechnical fattening cycle, we propose a protocol based on zootechnical and veterinary health standards managed by a laboratory (Figure 3). This protocol aims to shorten the breeding time, reduce the production costs per kilogram of meat through the distribution of the tomato pulp produced locally in the north and south of Algeria and obtain meat of good organoleptic and bacteriological quality.

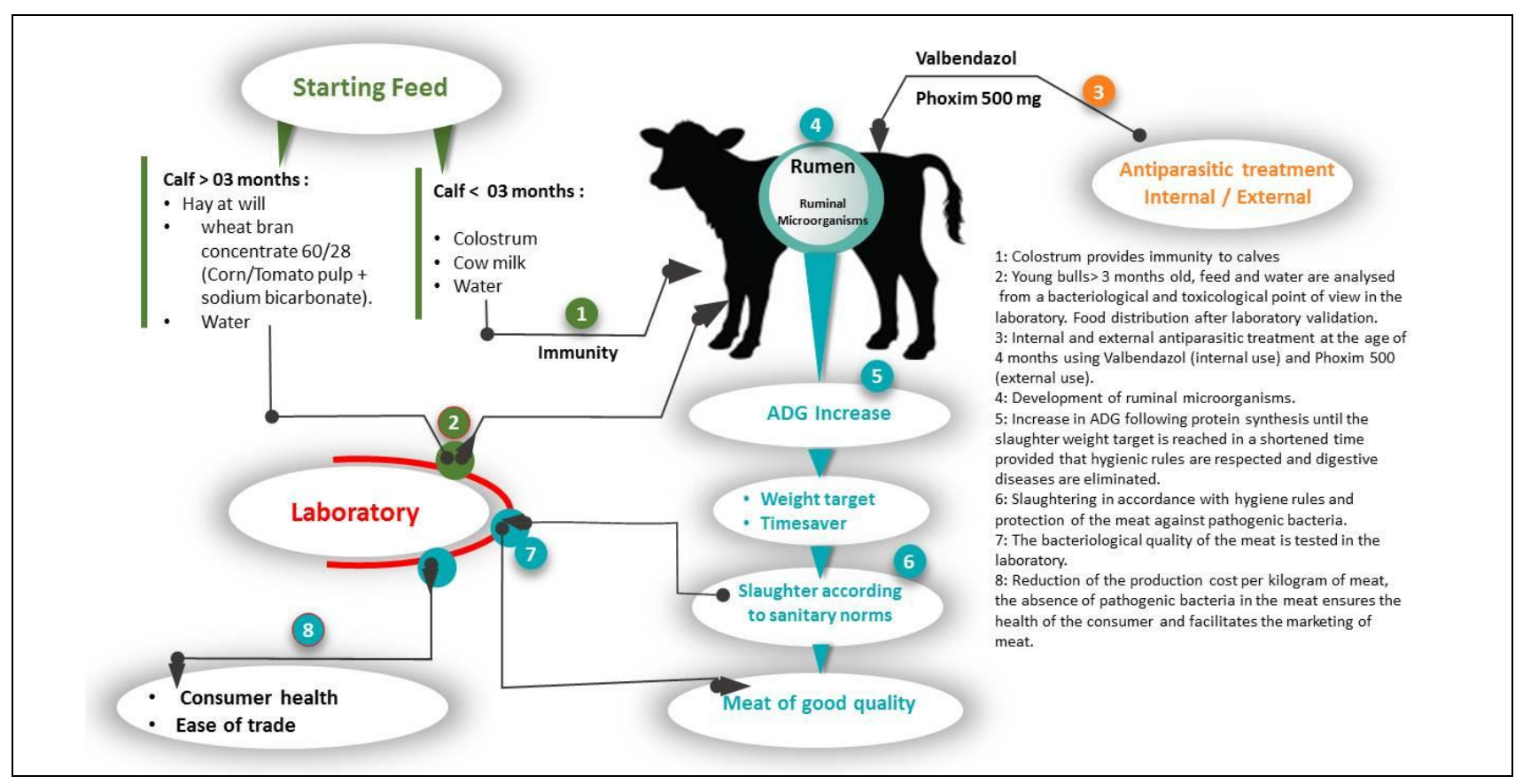

Figure 3. Fattening protocol proposed to Algerian mixed young breed bulls 


\section{CONCLUSIONS}

Algerian mixed-breed young bulls have an acceptable fattening index with the F2 ration -which was composed mainly by tomato pulp and supplemented with Sodium Bicarbonate - which was not optimal but still remains an acceptable solution nonetheless. It also allows rapid slaughter weight to be obtained as a consequence of the application of the proposed protocol.

The proposed protocol is considered a guide because it gives breeders the advantage of shortening the duration of the fattening cycle, allows assistance and monitoring by the laboratory of the feed and water distributed to the young bulls at the start of the fattening cycle as well as the analysis of faeces in the event of digestive disorders and the organoleptic and bacteriological control of the meat obtained at the end of the fattening cycle.

Author Contributions: H.S. designed the fattening protocol; A.F. collected data; H.S. Achieving the analyzes; L.A. coordination and corrections of the paper; H.S. Wrote the paper; A.S. Statistical analysis of data.

\section{Acknowledgments}

This research did not receive any specific grant from funding agencies in the public, commercial, or not-for-profit sectors.

\section{Conflicts of Interest}

The authors declare that they do not have any conflict of interest.

\section{REFERENCES}

1. Algerian Ministry of Agriculture. Annual review of agricultural activity; 2018. 24 p. Available from: http://madrp.gov.dz/agriculture/statistiques-agricoles.

2. Blanco M, Ripoll G, Albertí P, Sanz A, Revilla R, Villalba D, et al. Effect of early weaning on performance, carcass and meat quality of spring-born bull calves raised in dry mountain areas. Livest. Sci. 2008; 115(2-3): 226-234.

3. Dagnelie P. Theoretical and Applied Statistics. 3rd edition, Louvain-la-Neuve, De Boeck Superieur (Belgium), 2013.

4. FAO, IFAD, WFP. The State of Food Insecurity in the World. The multiple dimensions of food security. Rome. FAO, 2013; 56 p. Available from: http://www.fao.org/3/i3434e/i3434e.pdf.

5. FAO. World meat production in 2018, FAO, 2018; Available from: http://www.fao.org.

6. Feliachi K. National Report on Animal Genetic Resources: Algeria national commission ANGR; 2003.

7. Genzebu D, Tesfay G. The role of bacteria in nitrogen metabolism in the rumen with emphasis of cattle. RJAEM. 2015; 4(7): 282-290.

8. Górka P, Schurmann BL, Walpole ME, Błońska A, Li S, Plaizier JC. Effect of increasing the proportion of dietary concentrate on gastrointestinal tract measurements and brush border enzyme activity in Holstein steers. JDS. 2017; 100(6): 4539-4551.

9. Imani M, Mirzaei M, Baghbanzadeh-Nobari B, Ghaffari MH. Effects of drilling provision to dairy calves on growth performance and rumen fermentation: A meta-analysis and meta-regression. JDS. 2017; 100(2): 1136-1150. Available from: https://doi.org/10.3168/jds.2016-11561.

10. Kazemi-Bonchenari M, Salem AZM, López S. Influence of barley grain particle size and treatment with citric acid on digestibility, ruminal fermentation and microbial protein synthesis in Holstein calves. CUP. 2017; 11(8): $1295-1302$.

11. Mapinfo. Maps of hydrographic networks in Algeria; 2019; Available from: https://app.box.com/s/7u4i3m0pnt3sz118iqx7.

12. ONAB. Annual report National Livestock Feed Board; 2019. 15 p. Available from: http://www.onabnutrition.dz/article_7.htm.

13. Pazoki A, Ghorbani GR, Kargar S, Sadeghi-Sefidmazgi A, Drackley JK, Ghaffari MH. Growth performance, nutrient digestibility, ruminal fermentation, and rumen development of calves during transition from liquid to solid feed: Effects of physical form of starter feed and drilling provision. Anim. Feed Sci. Technol. 2017; 234:173-185.

14. Sauvant D, Giger-Reverdin S. Quantitative approach to acidosis in ruminants. Bulletin of the French Veterinary Academy, French Veterinary Academy. 2015; 168(3): 260-266. 10.4267/2042/57937. HAL Id: hal-01413564 Available from: https://hal.archives-ouvertes.fr/hal-01413564.

15. Senevirathne N D, Anderson JL, Gibbons WR, Clapper JR. Growth performance of calves fed microbially enhanced soy protein in pelleted starters. JDS. 2017; 100(1):199-212. 
16. Sultan JI, Javaid A, Nadeem M, Akhtar MZ, Mustafa MI. Effect of varying ruminally degradable to ruminally undegradable protein ratio on nutrient intake, digestibility and $\mathrm{N}$ metabolism in Nili Ravi buffalo calves (Bubalusbubalis). Livest. Sci. 2009; 122(2-3): 130-133.

17. Wang C, Liu Q, Zhang YL, Pei CX. Effects of isobutyrate supplementation in pre- and post-weaned dairy calves diet on growth performance, rumen development, blood metabolites and hormone secretion. CUP. 2017; 11(5): 794-801. 